\title{
ACKNOWLEDGMENTS
}

For their support and friendship, I would like to thank my parents, Kirsten and Eitel Friedrich Höcker, and my friends and colleagues, whose encouragement has helped me to complete this book: Alison Cool, Rüdiger Campe, Marco Clausen, Kijan Espahangizi, Christiane Frey, Patrick Greaney, Jason Groves, Wolf Kittler, Andrea Krauß, Jörg Kreienbrock, David Martyn, Peri Mason, Ulrich Plass, Tom Roberts, Matthias Rothe, Ann Schmiesing, Jochen Steinbicker, Davide Stimilli, Elisabeth Strowick, Ellwood Wiggins, Meredith Miller and my friends from the RCC Boulder. I am, indeed, particularly grateful to Paul Fleming for his generous support and advice, and to Helmut Müller-Sievers for being a diligent, critical, and generous reader of my manuscript, and for having pushed me to make this book better. It would not have been the same book without his ingenious advice.

An earlier version of chapter 3 appeared under the title "In Citation: 'A Violation of the Law of Boundaries' in Schiller and Kleist," Germanic Review: Literature, Culture, Theory 89, no. 1: 60-75 
(https://www.tandfonline.com). I am grateful to the press for allowing its reprinting here. I would also like to express my gratitude to the board and the editors of the Signale series at Cornell University Press, and to the two anonymous readers of my manuscript, whose advice and criticism has significantly contributed to its improvement. 


\section{The Case of Literature}


